\title{
Body size preference and body weight perception among two migrant groups of non-Western origin
}

\author{
Mary Nicolaou ${ }^{1,2, *}$, Colleen Doak ${ }^{2}$, Rob van Dam ${ }^{2,3}$, Karen Hosper ${ }^{1}$, Jaap Seidell ${ }^{2}$ \\ and Karien Stronks ${ }^{1}$ \\ 'Department of Social Medicine, Academic Medical Centre, University of Amsterdam, PO Box 22660, 1100 \\ DD Amsterdam, The Netherlands: ${ }^{2}$ Department of Nutrition and Health, Institute for Health Sciences, \\ VU University, Amsterdam, The Netherlands: ${ }^{3}$ Department of Nutrition, Harvard School of Public Health, \\ Boston, MA, USA
}

Submitted 7 December 2007: Accepted 2 May 2008: First published online 11 July 2008

\begin{abstract}
Objectives: To evaluate body size preference, body weight perception and their relationship with actual weight in two migrant groups of non-Western origin, Turks and Moroccans; additionally, to study the association between body size preference and acculturation.

Design: Cross-sectional study.

Setting: Amsterdam, The Netherlands.

Subjects and methods: Males and females (18-30 years) were randomly selected from the population registry ( $n 451$ ); participants, or at least one of their parents, were born in Turkey or Morocco. Body size preference was assessed using seven silhouette drawings and body weight perception was assessed by asking participants' opinion of own weight. Acculturation variables were generation status and two scale measures, cultural orientation and social contacts.

Results: Participants showed preference for a thin body size. The discrepancy between ideal and current size was significant in women but not men $(P<0 \cdot 001)$. Perceived current body size was correlated with BMI (Spearman's correlation coefficient $0 \cdot 60, P<0 \cdot 001$ (men) and $0 \cdot 73, P<0 \cdot 001$ (women)). Among overweight participants $\left(\mathrm{BMI}=25 \cdot 0-29 \cdot 9 \mathrm{~kg} / \mathrm{m}^{2}\right), 63-82 \%$ of men and $35 \%$ of women perceived themselves as 'average'. Paying attention to own body weight was associated with a discrepancy between ideal and current size among women and with perceiving oneself as 'overweight' among men. Body size preference was not significantly associated with the three acculturation variables.

Conclusion: We did not observe a preference for large body sizes in these two non-Western migrant groups. Similar to Western populations, most women wished to be thinner than they were. This was not the case among men, the majority of whom were also unaware of being overweight.
\end{abstract}

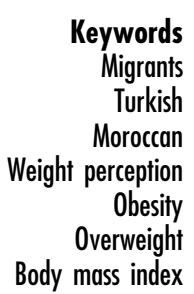

Overweight and obesity are a major public health problem and are associated with increased risk for type 2 diabetes, CVD and several types of cancer ${ }^{(1)}$. Their prevalence is reaching epidemic proportions, with an estimated 1 billion overweight and 300 million obese adults worldwide $^{(2)}$. Among non-Western migrants, which represent an increasing proportion of many Western populations ${ }^{(3)}$, the prevalence of overweight and obesity is often higher than that of host populations ${ }^{(4-6)}$. In The Netherlands more than half of the general adult population is either overweight ( $51 \%$ of males, $42 \%$ of females) or obese (10\% of males, $12 \%$ of females) ${ }^{(7)}$. In two of the main migrant groups of non-Western origin, Turks and Moroccans, it is estimated that $25-32 \%$ of women and $37-44 \%$ of men are overweight while $39-40 \%$ of women and $13-16 \%$ of men are obese ${ }^{(8,9)}$.

Public health promotion efforts aimed at overweight prevention often proceed from the assumption that most individuals prefer to be thin and that the first step in motivating individuals to lose weight is to raise awareness of weight status among those with overweight ${ }^{(10)}$. This approach is justified for Western populations that value thinness in women and lean, muscular physiques in men $^{(11-13)}$, but where awareness of overweight among those with overweight is often low ${ }^{(14,15)}$. However, this assumption might not hold for non-Western migrant groups among whom body size preference may differ. For example, in many traditional non-Western cultures 
large bodies in both males and females are associated with prosperity and health ${ }^{(16-21)}$. Migrants originating from non-Western societies may adhere to the ideals from their traditional cultures. Although this may protect them from experiencing dissatisfaction with their body size, it may also negatively influence the motivation for weight control or weight loss.

On the other hand, living in a Western society is also likely to influence the preferred body size of migrants through the process of acculturation ${ }^{(22)}$. Acculturation is a concept that 'comprehends those phenomena which result when groups of individuals having different cultures come into continuous first-hand contact with subsequent changes in the original culture patterns of either or both groups $^{,(23)}$, usually with a greater change taking place in the 'minority' group ${ }^{(24)}$. The expectation is that migrants are likely to adopt the body size ideals of their 'host' peers. Thus, highly acculturated migrants to Western societies would develop a preference for thinner figures.

That culture influences body size preference has been the rationale of many studies researching this topic among different ethnic groups. However, many of the studies of this topic have either focused on non-Western populations in their country of origin ${ }^{(19,20,25-28)}$ or have been conducted among US ethnic minority groups ${ }^{(29-32)}$. Few studies have considered this issue among nonWestern migrants to European countries ${ }^{(33-36)}$. Likewise, the association between body size preference and acculturation among ethnic minorities has seldom been studied in Europe. We found two UK studies, one that reported similar attitudes to body size among secondgeneration Asian women and white British women ${ }^{(34)}$ and another where Kenyan Asians residing in the UK were more similar to white British women in their body size preferences than to women still living in Kenya ${ }^{(36)}$. Considering that body size preference may be an important factor in motivating individuals to lose weight, information about this determinant among European migrants is necessary.

Two of the largest non-Western migrant groups in Western Europe originate from Turkey (The Netherlands, Germany, Denmark, Sweden) and Morocco (The Netherlands, Belgium, France, Spain). Migration from Turkey and Morocco was encouraged in the 1970s in order to fill labour shortages, particularly for lower manual positions. The initial migrants came from particularly deprived areas of their home country. Since that time further migration has occurred due to family reunification and formation, with many young Turkish and Moroccan adults choosing partners from their country of origin ${ }^{(37)}$. In The Netherlands many reside in the larger cities; in Amsterdam, persons of Turkish or Moroccan origin form respectively 5\% and 9\% of the total population ${ }^{(38)}$.

Literature from Morocco indicates that overweight and obesity prevalence, particularly among women, is on the increase and that this may be partly due to a tradition that values plumpness ${ }^{(16,17,39)}$. Although we found literature that indicates high overweight and obesity prevalence in Turkey $^{(40,41)}$, we found no studies of body size preference among Turkish adults. Anecdotal evidence indicates that, also in Turkey, there is a tradition of preference for large figures.

As already mentioned, the prevalence of overweight and obesity among Turkish and Moroccan migrants to The Netherlands is high. However, there is little information about body size preference (the body size considered to be 'ideal') or the perception of overweight (whether individuals classify their body weight correctly) among these two migrant populations. It may be that a preference for larger figures and/or the misperception of overweight is highly prevalent in these groups, which would have important implications for intervention development. Therefore the present study aimed to:

1. Evaluate body size preference and body weight perception among young men and women of Turkish and Moroccan origin.

2. Investigate whether preference and perception are related to actual body weight and to whether individuals pay attention to their body weight.

3. Examine the association between body size preference and acculturation level.

\section{Methods}

\section{Study population}

Participants for the present study were 18-30-year-olds who took part in LASER, a study of health behaviour among Turks and Moroccans aged 10 to 30 years living in Amsterdam, The Netherlands. In the LASER study a random sample of people born in Turkey or Morocco or with at least one parent born in Turkey or Morocco was drawn from the Amsterdam municipal population register. Participants born in Turkey or Morocco were classified as first-generation migrants. Second-generation migrants were those born in The Netherlands and who had at least one parent born in either Turkey or Morocco. As mentioned earlier, migration to the Netherlands from Turkey and Morocco began in the 1970s. Therefore, the majority of adult Turks and Moroccans are of the first generation, as has been observed in studies that have included adults $^{(42)}$. The LASER study focused on younger participants in order to ensure more equal representation of the second generation.

The total Turkish sample consisted of 1556 persons. Approximately $13 \%$ of the sample could not be traced because of incorrect address information. Of the 1354 respondents who could be traced, 768 participated in the study (57\%). Most cases of 'non-response' were due to refusals to participate $(32 \%)$ or not being able to contact potential participants after three attempts (12\%). The 
Moroccan sample consisted of 995 individuals of whom $12 \%$ had incorrect address information. Of the 872 persons who could be traced, 476 participated in the study (55\%). Within the non-response group, 26\% refused to participate and approximately $19 \%$ could not be reached after three attempts. The study population is similar to the Turkish and Moroccan population aged 10-30 years living in Amsterdam, according to sex, generational status (country of birth) and city district; except for the Moroccan male population, among whom the age category 20-30 years is under-represented, and participants from one city district being slightly over-represented.

For the current study we analysed participants aged 18-30 years ( $n$ 567). We excluded respondents with missing information on body weight perception ( $n$ 50) and BMI ( $n$ 66) to end with a total sample size of 451.

\section{Data collection}

Face-to-face interviews were held from April 2003 until December 2004, by trained interviewers of the same ethnic background and sex. A structured questionnaire was used; this was available in Dutch, Turkish or Moroccan Arabic so that the interview could be held in the participants' language of preference. Included were questions about demographics, socio-economic status and migration status. Acculturation was evaluated using a proxy measure, place of birth (generation), as well as scale measures of the level of social contact with ethnic Dutch (three questions on social contacts in leisure time) and orientation towards Dutch society (ten items measuring language and media use, shopping preference and emancipation as examples of Western norms and values). The data collection strategy, the questionnaire design and the acculturation measures have been fully described elsewhere $^{(42)}$.

\section{Body size preference and body weight perception}

Body size preference was evaluated using seven silhouette drawings developed by Collins ${ }^{(43)}$. Respondents were asked to select the silhouette that most corresponded to they way they currently look and also to select the ideal silhouette for themselves. A discrepancy score was calculated by subtracting the ideal from the current silhouette as was done by Fallon and Rozin ${ }^{(44)}$. Participants were also asked to select ideals for members of the same sex and opposite sex.

Body weight perception was evaluated by how participants described their body weight; answer categories included 'thin', 'average' or 'overweight'. Participants received no specific instructions relating to this question, therefore the answers obtained are not standardised but reflect individuals' personal evaluations. Finally, we asked 'Do you pay attention to your weight?' Possible answers were either 'yes' or 'no'. We formulated this question in a neutral way to avoid the association with dieting to lose weight.

\section{Measurement of body weight}

Participants were weighed and measured during the home visit. Weight was measured using an electronic scale to the nearest $0 \cdot 1 \mathrm{~kg}$ after removal of shoes, jackets, heavier clothing and pocket contents. Height was measured twice without shoes in an upright position with a measuring tape and ruler to the nearest $0 \cdot 1 \mathrm{~cm}$. We calculated BMI as weight divided by the square of height $\left(\mathrm{kg} / \mathrm{m}^{2}\right)$. Underweight was classified as having a BMI lower than $18.5 \mathrm{~kg} / \mathrm{m}^{2}$. There were six participants who fell into this category (two Moroccan women, two Turkish women, one Moroccan man and one Turkish man). We chose to include them together with the normalweight group for the analyses. Due to logistic problems not all participants could be weighed during the interview. In these cases ( $40 \%$ of all participants) weight and height were based on self-report. We performed additional analyses to explore the impact on our results. We found no difference in the prevalence of overweight between self-reporters and the weighed group. We also tested mean BMI between the two groups using the Mann-Whitney test and found no differences in BMI between them, with the exception of Moroccan women where median BMI was $22 \cdot 3 \mathrm{~kg} / \mathrm{m}^{2}$ in the self-reporters $v$. $24 \cdot 1 \mathrm{~kg} / \mathrm{m}^{2}$ in the measured group $(P=0 \cdot 05)$. Finally, we stratified according to self-report and compared on the basis of demographics, socio-economic status, acculturation variables and perception variables, but found no significant differences between them. We therefore decided to include the self-reporters in the analyses in order to maximise our sample size.

\section{Statistical analyses}

We analysed data using the Statistical Package for the Social Sciences statistical software package version 12 (SPSS Inc., Chicago, IL, USA). The sample was stratified according to sex and ethnicity for all analyses. For categorical variables we applied the $\chi^{2}$ test. Differences in body size preference and weight awareness between groups of respondents were tested using the MannWhitney test. Differences within groups were tested using the Wilcoxon signed-rank test. Spearman's rank correlations were calculated for the relationships of current and ideal silhouettes (body size preference) and BMI. In order to explore the association with acculturation we performed the analyses with the 'ideal' silhouette as dependent variable.

\section{Results}

Table 1 summarises the participants' characteristics. There were some statistically significant differences between the groups. Fewer Moroccan men were married or had children compared with the other groups. Within the ethnic groups, more women were married, had children and 
Table 1 Participant characteristics: male and female migrants of non-Western origin residing in Amsterdam, 2003-2004

\begin{tabular}{|c|c|c|c|c|c|c|c|c|}
\hline & \multicolumn{4}{|c|}{ Men } & \multicolumn{4}{|c|}{ Women } \\
\hline & \multicolumn{2}{|c|}{$\begin{array}{l}\text { Turkish } \\
(n \text { 169) }\end{array}$} & \multicolumn{2}{|c|}{$\begin{array}{c}\text { Moroccan } \\
\quad(n 56)\end{array}$} & \multicolumn{2}{|c|}{$\begin{array}{l}\text { Turkish } \\
(n \text { 122) }\end{array}$} & \multicolumn{2}{|c|}{$\begin{array}{c}\text { Moroccan } \\
(n \text { 104) }\end{array}$} \\
\hline \multicolumn{9}{|l|}{ Demographics } \\
\hline Mean (SD) age (years) & $23 \cdot 0$ & $4 \cdot 3$ & $21 \cdot 6$ & 3.4 & $24 \cdot 6$ & $4 \cdot 3$ & $23 \cdot 4$ & $4 \cdot 2$ \\
\hline Married $(\%)^{*}$ & \multirow{2}{*}{\multicolumn{2}{|c|}{$\begin{array}{l}39 \cdot 1 \\
31 \cdot 4\end{array}$}} & \multirow{2}{*}{\multicolumn{2}{|c|}{$16 \cdot 1$}} & \multicolumn{2}{|c|}{$55 \cdot 2$} & \multicolumn{2}{|c|}{$49 \cdot 0$} \\
\hline Has children $(\%)^{\star}$ & & & & & & & & \\
\hline \multicolumn{9}{|l|}{ Socio-economic status } \\
\hline \multicolumn{9}{|l|}{ Education level (\%) } \\
\hline 1 (low) & \multicolumn{2}{|c|}{$12 \cdot 9$} & \multicolumn{2}{|c|}{$7 \cdot 3$} & \multicolumn{2}{|c|}{$18 \cdot 3$} & \multicolumn{2}{|c|}{$16 \cdot 8$} \\
\hline 2 & \multicolumn{2}{|c|}{$28 \cdot 2$} & \multirow{2}{*}{\multicolumn{2}{|c|}{$\begin{array}{l}14 \cdot 5 \\
58 \cdot 2\end{array}$}} & & & \multicolumn{2}{|c|}{$21 \cdot 8$} \\
\hline 3 & \multicolumn{2}{|c|}{$45 \cdot 4$} & & & & & \multirow{2}{*}{\multicolumn{2}{|c|}{$\begin{array}{l}37 \cdot 6 \\
23 \cdot 8\end{array}$}} \\
\hline 4 (high) & \multicolumn{2}{|c|}{$13 \cdot 5$} & \multicolumn{2}{|c|}{$20 \cdot 0$} & \multicolumn{2}{|c|}{$\begin{array}{l}31 \cdot 5 \\
11 \cdot 7\end{array}$} & & \\
\hline \multicolumn{7}{|l|}{ Work status (\%) } & & \\
\hline Student & \multicolumn{2}{|c|}{$37 \cdot 6$} & \multicolumn{2}{|c|}{$\begin{array}{l}54 \cdot 7 \\
37 \cdot 7\end{array}$} & & & \multicolumn{2}{|c|}{$35 \cdot 3$} \\
\hline Paid employment & \multicolumn{2}{|c|}{$52 \cdot 2$} & & & & & & \\
\hline Unemployed/home maker & & & & & & & & \\
\hline Acculturation & & & & & & & & \\
\hline First generation $(\%)^{\star}$ & & & & & & & & \\
\hline Social contacts with Dutch & & & & & & & & \\
\hline High (\%) & & & & & & & & \\
\hline Cultural orientation to Dutch society† & & & & & & & & \\
\hline High (\%) & & & & & & & & \\
\hline Body weight & & & & & & & & \\
\hline Mean (SD) BMI $\left(\mathrm{kg} / \mathrm{m}^{2}\right)$ & $24 \cdot 5$ & $3 \cdot 2$ & $23 \cdot 4$ & $2 \cdot 8$ & $24 \cdot 6$ & $4 \cdot 3$ & $24 \cdot 1$ & $4 \cdot 1$ \\
\hline Overweight (\%) & & & & & & & & \\
\hline Obesity (\%) & & & & & & & & \\
\hline
\end{tabular}

Education level: $1=$ never been to school or primary school only; 2 =lower vocational and lower secondary education; $3=$ intermediate vocational and intermediate/higher secondary education; 4 = higher vocational education and university.

*Within ethnic groups, women more likely to be from first generation, be married and have children, $P<0.01$.

tTurkish participants had lower cultural orientation than Moroccan participants, $P<0.001$.

No other significant differences between Turkish and Moroccan participants $(P>0 \cdot 05)$.

were not in paid employment. Moroccan men and women had a slightly higher education level than the Turkish participants although this was not statistically significant $(P=0.08$ in men and $P=0.07$ in women). BMI values ranged from 15.6 to $36 \cdot 7 \mathrm{~kg} / \mathrm{m}^{2}$. Women were more often first-generation migrants. The majority of participants had a low level of social contact with ethnic Dutch $(22 \cdot 1-33 \cdot 9 \%$ had high a level of contact) with no significant differences between the groups. More Moroccans than Turks were highly culturally oriented towards Dutch society $(42 \cdot 0 \% v .25 \cdot 6 \%$ of women and $48 \cdot 2 \% v \cdot 35 \cdot 5 \%$ of men, $P<0 \cdot 001$ ), but this was still less than half of the Moroccan group. More Turkish men were overweight $(35 \cdot 5 \%)$ and the prevalence of overweight and obesity was $37 \cdot 6 \%$ among Turkish women and $34 \cdot 6 \%$ among Moroccan women.

Table 2 shows the results of body size preference, body weight perception and the percentage of participants who pay attention to their weight. Men's preferred size was similar to their current size whereas women selected an ideal that was significantly smaller than their current size. Based on the calculated discrepancy between current and ideal silhouette, the majority of women (60.3\% Turkish and $57 \cdot 7 \%$ Moroccan) preferred a smaller size for themselves whereas this was less the case among the men, $21 \cdot 8 \%$ and $29 \cdot 0 \%$ for the Moroccan and Turkish men respectively.
All groups chose a thinner ideal size for themselves than for others of their own sex. Further, Turkish men and women had a significantly thinner ideal for members of the opposite sex than did Moroccans. Most of the men $(67 \cdot 7-70 \cdot 9 \%)$ and almost half the women $(47 \cdot 1-51 \cdot 6 \%)$ perceived their body weight to be 'average'. The majority of women $(60 \cdot 2-69 \cdot 0 \%)$ and Turkish men (56.8\%) reported that they pay attention to their weight, whereas less than half $(45 \cdot 5 \%)$ of Moroccan men did so.

Table 3 shows mean BMI according to silhouette selected to represent current body size. The correlation coefficient for BMI and current silhouette was low but statistically significant in all groups. We tested ethnic differences and found that per silhouette Moroccan women had lower BMI than Turkish women $(P<0 \cdot 05)$, while there were no differences between the men.

Figure 1 shows body weight perception according to BMI category. Here we see that a relatively large proportion of men who are overweight (BMI $=25 \cdot 0-29 \cdot 9 \mathrm{~kg} /$ $\mathrm{m}^{2}$ ) described themselves as 'average', $63.0 \%$ of Turkish men and $82 \cdot 0 \%$ of Moroccan men. One-third of overweight Turkish and Moroccan women respectively described themselves as 'average'.

Table 4 shows that body size preference did not differ according to generation status, level of cultural orientation to Dutch society or level of social contacts with ethnic Dutch. Among Turkish women who have more 
Table 2 Body size preference, body weight perception and percentage paying attention to own weight: male and female migrants of non-Western origin residing in Amsterdam, 2003-2004

\begin{tabular}{|c|c|c|c|c|c|c|c|c|}
\hline & \multicolumn{4}{|c|}{ Men } & \multicolumn{4}{|c|}{ Women } \\
\hline & \multicolumn{2}{|c|}{$\begin{array}{l}\text { Turkish } \\
\text { (n 169) }\end{array}$} & \multicolumn{2}{|c|}{$\begin{array}{c}\text { Moroccan } \\
(n 56)\end{array}$} & \multicolumn{2}{|c|}{$\begin{array}{l}\text { Turkish } \\
(n \text { 122) }\end{array}$} & \multicolumn{2}{|c|}{$\begin{array}{c}\text { Moroccan } \\
(n \text { 104) }\end{array}$} \\
\hline & Mean & SD & Mean & SD & Mean & SD & Mean & SD \\
\hline \multicolumn{9}{|c|}{ Body size preference (based on silhouette) } \\
\hline Current body shape & $4 \cdot 1$ & $1 \cdot 0$ & $4 \cdot 1$ & 0.8 & $4 \cdot 3$ & $1 \cdot 3$ & $4 \cdot 6$ & $1 \cdot 0$ \\
\hline Ideal size for self* & $4 \cdot 0$ & 0.7 & $4 \cdot 2$ & 0.5 & $3 \cdot 4$ & 0.8 & 3.9 & $0 \cdot 7$ \\
\hline Ideal for others of own sext & $4 \cdot 1$ & 0.7 & $4 \cdot 4$ & $0 \cdot 7$ & 3.9 & 0.9 & $4 \cdot 1$ & $0 \cdot 6$ \\
\hline \multirow[t]{2}{*}{ Ideal opposite sex $\ddagger$} & $3 \cdot 8$ & 0.6 & $4 \cdot 2$ & $1 \cdot 1$ & 3.9 & 0.9 & $4 \cdot 2$ & $0 \cdot 6$ \\
\hline & \multicolumn{2}{|c|}{$\%$} & \multicolumn{2}{|c|}{$\%$} & \multicolumn{2}{|c|}{$\%$} & \multicolumn{2}{|c|}{$\%$} \\
\hline Would like to be thinner§ & \multicolumn{2}{|c|}{$29 \cdot 0$} & \multicolumn{2}{|c|}{$21 \cdot 8$} & \multicolumn{2}{|c|}{$60 \cdot 3$} & \multirow{2}{*}{\multicolumn{2}{|c|}{$57 \cdot 7$}} \\
\hline \multicolumn{7}{|c|}{ Body weight perception (describes weight as) } & & \\
\hline Thin & \multicolumn{2}{|c|}{$11 \cdot 4$} & \multicolumn{2}{|c|}{$12 \cdot 7$} & \multicolumn{2}{|c|}{$12 \cdot 7$} & \multicolumn{2}{|c|}{$7 \cdot 7$} \\
\hline Average & \multicolumn{2}{|c|}{$67 \cdot 7$} & \multicolumn{2}{|c|}{$70 \cdot 9$} & \multicolumn{2}{|c|}{$51 \cdot 6$} & \multicolumn{2}{|c|}{$47 \cdot 1$} \\
\hline Overweight & \multicolumn{2}{|c|}{$21 \cdot 0$} & \multicolumn{2}{|c|}{$16 \cdot 4$} & \multicolumn{2}{|c|}{$35 \cdot 7$} & \multicolumn{2}{|c|}{$45 \cdot 2$} \\
\hline Pays attention to weight & \multicolumn{2}{|c|}{$56 \cdot 8$} & \multicolumn{2}{|c|}{$45 \cdot 5$} & \multicolumn{2}{|c|}{$69 \cdot 0$} & \multicolumn{2}{|c|}{$60 \cdot 2$} \\
\hline
\end{tabular}

${ }^{\star}$ Difference between ideal body size and current size significant for women, $P<0.001$.

tldeal for others larger than ideal for self: men $P<0.05$, women $P<0.001$.

$\ddagger$ Turkish men and women had smaller ideal for the opposite sex than Moroccan participants, $P<0.05$.

$\S$ Based on discrepancy in silhouettes chosen to represent ideal and current size.

contacts with ethnic Dutch the ideal silhouette was slightly thinner $(P=0 \cdot 06)$. Among second-generation men the ideal was slightly larger $(P=0.06$ in Turkish men and $P=0.09$ in Moroccan men).

Table 5 shows self-reported weight behaviour offset against the main outcome variables. There were no statistically significant differences between participants who reported watching their weight $v$. those who did not on the basis of preferred body size (mean silhouette), body size discrepancy (difference between current and ideal size) or overweight perception.

As the findings followed a similar trend for both ethnic groups we combined them and stratified according to sex in order to increase the power of our calculations. We found that more women reported paying attention to their weight if their preferred body size was smaller than their current body size $\left(\chi^{2}=6 \cdot 7, P=0 \cdot 01\right)$. Among men, this was the case if they perceived themselves to be overweight $\left(\chi^{2}=8 \cdot 8, P=0 \cdot 01\right)$.

\section{Discussion}

The present population-based study is the first to offer insight into the issue of body size preference and body weight perception among these two important European non-Western migrant groups. In our study we did not observe a preference for a large body size; in contrast, this group of Turkish and Moroccan participants selected relatively thin silhouettes to represent their ideal. The silhouette selected to represent current body size was correlated with BMI, indicating that individuals' perception of their body size is realistic. As is generally found in Western populations, the preferred body size among women was significantly thinner than their current size whereas this was not the case among men. Furthermore, a large proportion of overweight and obese men perceived their weight to be 'average', which may indicate greater acceptance of overweight. A discrepancy between ideal and current size was associated with paying attention to body weight in women. Among men, paying attention to body weight was associated with the perception of overweight. Finally, we did not observe an association between body size preference and acculturation variables such as generation status, social contacts with Dutch or orientation with Dutch society.

The study has some limitations that merit mention. First the response rate was quite low, 57\% among Turks and $55 \%$ among Moroccans, which means that our study population may not be representative of Turkish and Moroccan residents of The Netherlands. However, the response is comparable to that obtained by other studies of the same groups ${ }^{(9,45)}$, and our participants are comparable to the Turkish and Moroccan population living in Amsterdam. Second, we used a combination of both measured and self-reported data of weight and height. We tested the effect of this methodological issue but found no differences in the main outcomes between the self-reporters and the weighed group, indicating limited impact on our main conclusions. Third, we cannot rule out the possibility that participants gave socially desirable answers. As culture is likely to influence body size preference, our use of interviewers matched for sex and ethnicity may have minimised this possibility. Fourth, we cannot place the results from the study within the context of their host environment as we did not include ethnic Dutch participants. It may be that ethnic Dutch men and women prefer even thinner bodies. A study of 
Table 3 Mean BMI of participants according silhouette they selected to represent current body size: male and female migrants of non-Western origin residing in Amsterdam, 2003-2004

\begin{tabular}{|c|c|c|c|c|c|c|c|c|c|c|c|c|c|}
\hline \multicolumn{14}{|c|}{ Silhouette } \\
\hline \multicolumn{2}{|c|}{1} & \multicolumn{2}{|c|}{2} & \multicolumn{2}{|c|}{3} & \multicolumn{2}{|c|}{4} & \multicolumn{2}{|c|}{5} & \multicolumn{2}{|c|}{6} & \multicolumn{2}{|c|}{7} \\
\hline$n$ or Mean & $\%$ or SD & $n$ or Mean & $\%$ or SD & $n$ or Mean & $\%$ or SD & $n$ or Mean & $\%$ or SD & $n$ or Mean & $\%$ or SD & $n$ or Mean & $\%$ or SD & $n$ or Mean & $\%$ or SD \\
\hline
\end{tabular}

Men

Turkish
$n(\%)$

$n(\%)$
Mean (sD) BMI $\left(\mathrm{kg} / \mathrm{m}^{2}\right)$

$\begin{array}{cccc}2 & 1.2 & 6 & 3.6\end{array}$

Spearman's $\rho=0.66, P<0.001$

Moroccan

$n(\%)$

Mean (sD) BMI $\left(\mathrm{kg} / \mathrm{m}^{2}\right)$

$\begin{array}{llcc}- & - & 1 & 1.8\end{array}$

Spearman's $\rho=0.43, P<0.001$

Women*

Turkish

$n(\%)$

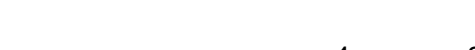

Moroccan

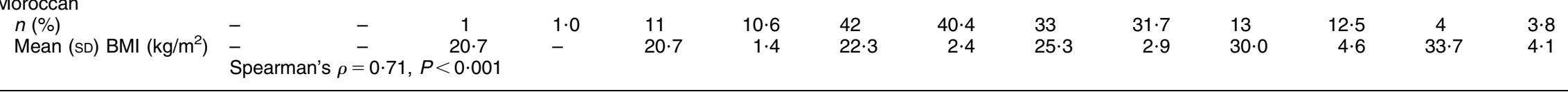

Ethnic groups combined: in men Spearman's $\rho=0.60, P<0.001$; in women Spearman's $\rho=0.73, P<0.001$.

*Significant difference between women in actual BMI according to selected silhouette, $P<0.05$. 


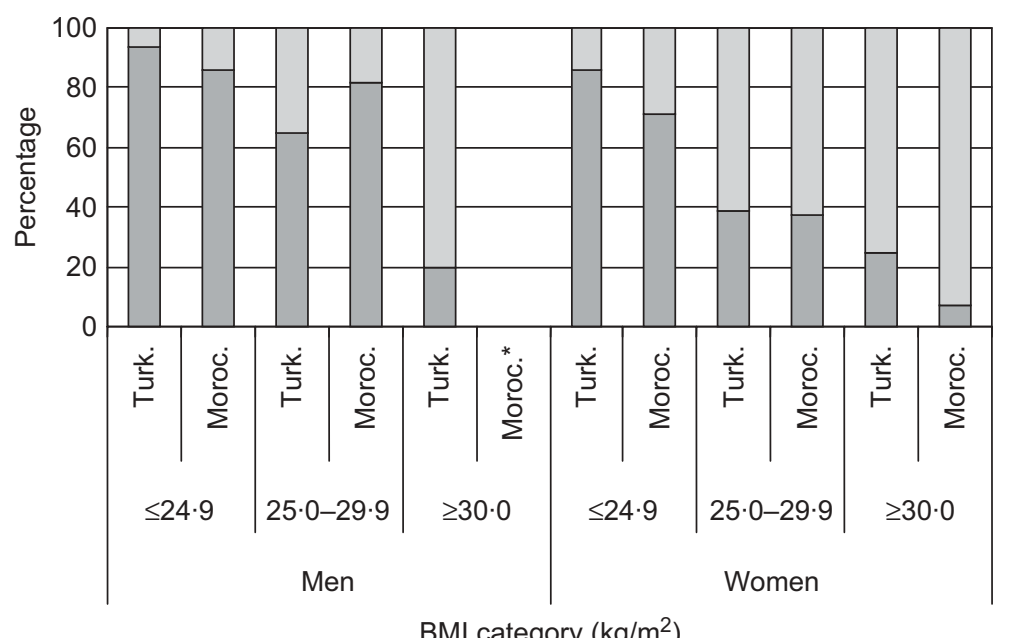

Fig. 1 Body weight perception ( $\square$, perceives self as thin; $\square$, perceives self as overweight) according to actual BMI in Turkish (Turk.) and Moroccan (Moroc.) male and female migrants residing in Amsterdam, 2003-2004. *Numbers insufficient $(n 2)$ to present results

Table 4 Acculturation and body size preference (mean silhouette chosen to represent ideal): male and female migrants of non-Western origin residing in Amsterdam, 2003-2004

\begin{tabular}{|c|c|c|c|c|}
\hline & \multicolumn{2}{|c|}{ Men } & \multicolumn{2}{|c|}{ Women } \\
\hline & $\begin{array}{l}\text { Turkish } \\
(n \text { 169) }\end{array}$ & $\begin{array}{l}\text { Moroccan } \\
\quad(n 56)\end{array}$ & $\begin{array}{l}\text { Turkish } \\
(n \text { 122) }\end{array}$ & $\begin{array}{c}\text { Moroccan } \\
(n \text { 104) }\end{array}$ \\
\hline \multicolumn{5}{|c|}{ Generation* } \\
\hline First & $3 \cdot 83$ & $4 \cdot 00$ & $3 \cdot 37$ & 3.94 \\
\hline Second & $4 \cdot 05$ & $4 \cdot 26$ & $3 \cdot 49$ & $3 \cdot 84$ \\
\hline \multicolumn{5}{|c|}{ Social contacts with Dutcht } \\
\hline Low & $4 \cdot 01$ & $4 \cdot 24$ & $3 \cdot 49$ & $3 \cdot 89$ \\
\hline High & $3 \cdot 80$ & $4 \cdot 00$ & $3 \cdot 21$ & $3 \cdot 91$ \\
\hline \multicolumn{5}{|c|}{ Cultural orientation to Dutch society } \\
\hline Low & 3.95 & $4 \cdot 14$ & $3 \cdot 46$ & $3 \cdot 86$ \\
\hline High & 3.95 & $4 \cdot 19$ & $3 \cdot 28$ & $3 \cdot 88$ \\
\hline
\end{tabular}

None of the differences by acculturation variables were statistically significant $(P>0 \cdot 05)$, although there were some borderline significant results as follows. ${ }^{\star} P=0.06$ in Turkish men, $P=0.09$ in Moroccan men.

tTurkish women, $P=0.06$.

Table 5 Pays attention to body weight $v$. body size preference and body weight perception: male and female migrants of non-Western origin residing in Amsterdam, 2003-2004

\begin{tabular}{|c|c|c|c|c|c|c|c|c|}
\hline & \multicolumn{4}{|c|}{ Men } & \multicolumn{4}{|c|}{ Women } \\
\hline & \multicolumn{2}{|c|}{ Turkish } & \multicolumn{2}{|c|}{ Moroccan } & \multicolumn{2}{|c|}{ Turkish } & \multicolumn{2}{|c|}{ Moroccan } \\
\hline & $\begin{array}{c}\text { No } \\
(n \text { 73) }\end{array}$ & $\begin{array}{l}\text { Yes } \\
(n \text { 94) }\end{array}$ & $\begin{array}{c}\text { No } \\
(n 30)\end{array}$ & $\begin{array}{l}\text { Yes } \\
(n \text { 25) }\end{array}$ & $\begin{array}{c}\text { No } \\
(n \text { 39) }\end{array}$ & $\begin{array}{c}\text { Yes } \\
(n 87)\end{array}$ & $\begin{array}{c}\text { No } \\
(n \text { 41) }\end{array}$ & $\begin{array}{c}\text { Yes } \\
(n 62)\end{array}$ \\
\hline \multicolumn{9}{|l|}{ Body size preference } \\
\hline Preferred silhouette, mean & $4 \cdot 0$ & 3.9 & $4 \cdot 1$ & $4 \cdot 2$ & $3 \cdot 4$ & $3 \cdot 3$ & $4 \cdot 0$ & 3.9 \\
\hline Would like to be thinner (\%)* & $27 \cdot 4$ & $30 \cdot 2$ & $16 \cdot 7$ & $28 \cdot 0$ & $48 \cdot 7$ & $65 \cdot 5$ & $46 \cdot 3$ & $64 \cdot 5$ \\
\hline \multicolumn{9}{|l|}{ Body weight perception } \\
\hline Perceives self as overweight (\%) & $17 \cdot 8$ & $23 \cdot 4$ & $13 \cdot 3$ & $20 \cdot 0$ & $41 \cdot 0$ & $33 \cdot 3$ & $34 \cdot 1$ & $51 \cdot 6$ \\
\hline
\end{tabular}

$\mathrm{No}=$ does not pay attention to body weight; Yes = pays attention to body weight. ${ }^{*}$ Based on discrepancy in silhouettes chosen to represent ideal and current size.

US residents aged 18-30 years that used similar figural stimuli showed that men tended to prefer figure 4 and women figure $3^{(46)}$. This preference is not dissimilar to the silhouettes chosen by participants in our study.
However it is not certain whether this population can be used as a reference considering that overweight and obesity prevalence is higher in the USA than in The Netherlands ${ }^{(7,47)}$. It may be that the overweight/obesity 
prevalence in the general population may influence body size preference as speculated by Cash $e t a l$. in their study of changes of body image among US college students ${ }^{(48)}$ and by Bennett et al. in a study of attitudes towards overweight in African Americans ${ }^{(49)}$. Finally, although the figural stimuli used in our study have not been validated for the Turkish and Moroccan populations, similar instruments have been widely used in various study populations which lends support to our choice of instrument ${ }^{(19,20,25,50)}$.

Much of the research conducted in this area originates in the USA and compares white American, African American, Hispanic and Asian groups. The results and conclusions have been mixed but two recent meta-analyses have shown that ethnic differences seem to be diminishing: Roberts et al. found that differences in body dissatisfaction between African American and white women were converging $^{(51)}$; Grabe and Hyde found that ethnic differences in the perception of body weight between women were small ${ }^{(30)}$. Our finding that that these groups of Turkish and Moroccan origin have a preference for thinner body size is consistent with the idea that a preference for thinness is common, particularly among women.

In addition, our study indicates that this preference is not related to acculturation, as might have been expected based on the findings of others ${ }^{(22,34,36,52)}$. However the comparison of these findings with ours is problematic due to differences in the measurement of acculturation. Furthermore, we measured a limited number of indicators of acculturation; it may be that other dimensions of acculturation (e.g. ethnic identity) and migration-related issues (e.g. acculturative stress) are more relevant for body size preference and the associated consequences thereof ${ }^{(53,54)}$. The issue of methodology has been highlighted by others and remains a barrier to understanding the relationships between acculturation, body size preference and body dissatisfaction ${ }^{(55,56)}$.

Our finding that a large proportion of women of nonWestern origin experience a discrepancy between desired and actual body size is similar to those among Western populations ${ }^{(14,15)}$. Interestingly, although the majority of women chose a thinner ideal body size for themselves (57.7-60.3\%), fewer women perceived themselves as 'overweight' $(35 \cdot 7-45 \cdot 2 \%)$, which implies that wanting to be thinner is not always related to the belief that one is overweight. Fitzgibbon et al. ${ }^{(32)}$ argue that these are two distinct issues, the discrepancy between the ideal and current body size is more likely to reflect body dissatisfaction and may be a factor that stimulates attention to weight-loss activities. Our observation that a larger majority of women pay attention to their weight if their perceived size is larger than their desired size supports this idea. Body dissatisfaction, whether appropriate or not, may be a stimulus for weight-watching behaviour among women and may contribute to reduced quality of life ${ }^{(57)}$ as well as to eating pathology ${ }^{(15,31)}$. The latter does not appear to differ for women of non-Western origin ${ }^{(32)}$.
Further research of this issue among these population groups is warranted. But in the meantime, interventions should be sensitive for potentially negative effects on women's dieting practices.

Two studies in Europe have shown a lower awareness of overweight among migrant-origin groups ${ }^{(33)}$, including South Asian groups ${ }^{(35)}$. Within our populations we observed that a high proportion of overweight men (63-82\%) and overweight women (35\%) perceived themselves as average. Although we cannot compare our group to the general population, the finding that more men than women are unaware of their overweight is consistent with that of others ${ }^{(14,58)}$. As mentioned previously, in a setting where overweight and obesity are common, overweight individuals may be more likely to experience themselves as being 'average'. This effect may be stronger among men whereas among women the socio-cultural stigma associated with overweight may dominate. Considering that paying attention to body weight is more prevalent among men who perceive themselves as overweight, it appears that raising awareness of weight status may be an important stimulus for weight-watching behaviour among men, including those of non-Western origin.

Although we did not aim to compare Turks and Moroccans with each other, we did observe some differences between these groups. Per silhouette selected to represent current body size Moroccan women had lower BMI levels. In other words, they viewed themselves as 'larger' than did Turkish women. In addition, Turkish women preferred a smaller ideal silhouette than did Moroccan women and both Turkish men and women preferred smaller sizes in members of the opposite sex. This apparently stronger preference for thinner body sizes among Turkish participants could be reflected in their more 'optimistic' choice of silhouette to represent themselves. Our finding of a thin body size ideal among this group is in line with a study in Turkey which showed that the desire to be thinner in Turkish adolescents is similar to that among adolescents in developed countries ${ }^{(59)}$. Among Moroccans there may be a greater acceptance for larger body sizes. As literature from Morocco indicates that adiposity in women is associated with higher social status ${ }^{(16,17)}$, it may be that Moroccans may be less concerned with thinness as an ideal. However, this is not entirely consistent with our finding that $45 \%$ of Moroccan women perceived themselves as 'overweight' even though the prevalence of overweight and obesity in this group was $36 \cdot 6 \%$ and that the majority of women, $57 \cdot 7 \%$, preferred a smaller body size. Comparable data from Turkey and Morocco would help in understanding these results.

\section{Conclusions}

In this first exploration of body size preference and body weight perception in young adults of Turkish and 
Moroccan origin, we did not observe a preference for large body sizes. Similar to Western populations, most women wished to be thinner than they were whereas this was less the case among men, the majority of whom were also unaware of being overweight.

Among the majority of men raising awareness of overweight appears to be an important intervention goal. However, caution is advisable when targeting women. Although a third do not perceive themselves to be overweight, the majority exhibit dissatisfaction with their body size which may make them susceptible to inappropriate dieting practices.

\section{Acknowledgements}

The LASER study was funded by The Netherlands Heart Foundation and The Netherlands Organisation for Health Research and Development (NWO, ZonMw). We declare no conflict of interests.

Authors' contributions: M.N., K.S. and K.H. designed the study. M.N. conducted the analysis and wrote the original draft with input from all the other authors.

\section{References}

1. Visscher TL \& Seidell JC (2001) The public health impact of obesity. Annu Rev Public Health 22, 355-375.

2. World Health Organization (2004) Obesity and overweight. In Global Strategy on Diet, Physical Activity and Health. Geneva: WHO.

3. International Organization for Migration (2004) World Migration 2005: Costs and Benefits of International Migration. Geneva: IOM.

4. Kumar BN, Meyer HE, Wandel M, Dalen I \& HolmboeOttesen G (2006) Ethnic differences in obesity among immigrants from developing countries, in Oslo, Norway. Int J Obes (Lond) 30, 684-690.

5. Tremblay MS, Perez CE, Ardern CI, Bryan SN \& Katzmarzyk PT (2005) Obesity, overweight and ethnicity. Health Rep 16, 23-34.

6. Wandell PE, Hjorleifsdottir SK \& Johansson SE (2003) Diabetes mellitus in Turkish immigrants in Sweden. Diabetes Metab 29, 435-439.

7. Schokker DF, Visscher TL, Nooyens AC, van Baak MA \& Seidell JC (2007) Prevalence of overweight and obesity in the Netherlands. Obes Rev 8, 101-107.

8. Brussaard JH, van Erp-Baart MA, Brants HA, Hulshof KF \& Lowik MR (2001) Nutrition and health among migrants in The Netherlands. Public Health Nutr 4, 659-664.

9. Dijkshoorn H, Uitenbroek DG \& Middelkoop BJ (2003) [Prevalence of diabetes mellitus and cardiovascular disease among immigrants from Turkey and Morocco and the indigenous Dutch population]. Ned Tijdschr Geneeskd 147, $1362-1366$.

10. Wammes B, Breedveld B, Looman C \& Brug J (2005) The impact of a national mass media campaign in The Netherlands on the prevention of weight gain. Public Health Nutr 8, 1250-1257.

11. Rodin J (1993) Cultural and psychosocial determinants of weight concerns. Ann Intern Med 119, 643-645.

12. Stice E (1994) Review of the evidence for a sociocultural model of bulimia-nervosa and an exploration of the mechanisms of action. Clin Psychol Rev 14, 633-661.
13. Pope Jr HG, Olivardia R, Gruber A \& Borowiecki J (1999) Evolving ideals of male body image as seen through action toys. Int J Eat Disord 26, 65-72.

14. Blokstra A, Burns CM \& Seidell JC (1999) Perception of weight status and dieting behaviour in Dutch men and women. Int J Obes Relat Metab Disord 23, 7-17.

15. Madrigal H, Sanchez-Villegas A, Martinez-Gonzalez MA, Kearney J, Gibney MJ, Irala J \& Martínez JA (2000) Underestimation of body mass index through perceived body image as compared to self-reported body mass index in the European Union. Public Health 114, 468-473.

16. Benjelloun S (2002) Nutrition transition in Morocco. Public Health Nutr 5, 135-140.

17. Mokhtar N, Elati J, Chabir R, Bour A, Elkari K, Schlossman NP, Caballero B \& Aguenaou H (2001) Diet culture and obesity in northern Africa. J Nutr 131, 887S-892S.

18. Becker AE, Gilman SE \& Burwell RA (2005) Changes in prevalence of overweight and in body image among Fijian women between 1989 and 1998. Obes Res 13, 110-117.

19. Al-Sendi AM, Shetty P \& Musaiger AO (2004) Body weight perception among Bahraini adolescents. Child Care Health Dev 30, 369-376.

20. Jackson RT, Rashed M \& Saad-Eldin R (2003) Rural urban differences in weight, body image, and dieting behavior among adolescent Egyptian schoolgirls. Int J Food Sci Nutr 54, 1-11.

21. Simeon DT, Rattan RD, Panchoo K, Kungeesingh KV, Ali AC \& Abdool PS (2003) Body image of adolescents in a multi-ethnic Caribbean population. Eur J Clin Nutr 57, 157-162.

22. Cachelin FM, Monreal TK \& Juarez LC (2006) Body image and size perceptions of Mexican American women. Body Image 3, 67-75.

23. Redfield R, Linton R \& Heskovitz MJ (1935) Outline for the study of acculturation. Am Anthropol N Series 9, 149-152.

24. Berry JW (1997) Immigration, acculturation and adaptation. Appl Psychol 46, 5-68.

25. Mciza Z, Goedecke JH, Steyn NP, Charlton K, Puoane T, Meltzer S, Levitt NS \& Lambert EV (2005) Development and validation of instruments measuring body image and body weight dissatisfaction in South African mothers and their daughters. Public Health Nutr 8, 509-519.

26. Rasheed P (1998) Perception of body weight and selfreported eating and exercise behaviour among obese and non-obese women in Saudi Arabia. Public Health 112, 409-414.

27. Siervo M, Grey P, Nyan OA \& Prentice AM (2006) A pilot study on body image, attractiveness and body size in Gambians living in an urban community. Eat Weight Disord 11, 100-109.

28. Shih MY \& Kubo C (2005) Body shape preference and body satisfaction of Taiwanese and Japanese female college students. Psychiatry Res 133, 263-271.

29. Cachelin FM, Rebeck RM, Chung GH \& Pelayo E (2002) Does ethnicity influence body-size preference? A comparison of body image and body size. Obes Res 10, 158-166.

30. Grabe S \& Hyde JS (2006) Ethnicity and body dissatisfaction among women in the United States: a meta-analysis. Psychol Bull 132, 622-640.

31. Bennett GG \& Wolin KY (2006) Satisfied or unaware? Racial differences in perceived weight status. Int J Behav Nutr Phys Act 3, 40.

32. Fitzgibbon ML, Blackman LR \& Avellone ME (2000) The relationship between body image discrepancy and body mass index across ethnic groups. Obes Res 8, 582-589.

33. Brug J, Wammes B, Kremers S, Giskes K \& Oenema A (2006) Underestimation and overestimation of personal weight status: associations with socio-demographic characteristics and weight maintenance intentions. J Hum Nutr Diet 19, 253-262. 
34. Bush HM, Williams RG, Lean ME \& Anderson AS (2001) Body image and weight consciousness among South Asian, Italian and general population women in Britain. Appetite 37, 207-215.

35. Patel S, Bhopal R, Unwin N, White M, Alberti KG \& Yallop J (2001) Mismatch between perceived and actual overweight in diabetic and non-diabetic populations: a comparative study of South Asian and European women. J Epidemiol Community Health 55, 332-333.

36. Furnham A \& Alibhai N (1983) Cross-cultural differences in the perception of female body shapes. Psychol Med 13, 829-837.

37. de Beer J \& Harmsen C (2003) Ethnic marriages. http:// www.cbs.nl/ (accessed January 2008).

38. Research and Statistics (2007) Population of Amsterdam according to ethnic origin. http://www.os.amsterdam.nl/ (accessed January 2008).

39. Rguibi M \& Belahsen R (2006) Body size preferences and sociocultural influences on attitudes towards obesity among Moroccan Sahraoui women. Body Image 3, 395-400.

40. Yumuk VD (2005) Prevalence of obesity in Turkey. Obes Rev 6, 9-10.

41. Ertem M, Bahceci M, Tuzcu A, Saka G, Ozturk U \& Gokalp D (2008) The association between high parity and obesity in women living in South-eastern Turkey. Eat Weight Disord 13, e4-e7.

42. Hosper K, Klazinga NS \& Stronks K (2007) Acculturation does not necessarily lead to increased physical activity during leisure time: a cross-sectional study among Turkish young people in the Netherlands. BMC Public Health 7, 230.

43. Collins ME (1991) Body figure perceptions and preferences among preadolescent children. Int $J$ Eat Disord 10 , 199-208.

44. Fallon AE \& Rozin P (1985) Sex differences in perceptions of desirable body shape. J Abnorm Psychol 94, 102-105.

45. Agyemang C, Ujcic-Voortman J, Uitenbroek D, Foets $M$ \& Droomers M (2006) Prevalence and management of hypertension among Turkish, Moroccan and native Dutch ethnic groups in Amsterdam, the Netherlands: The Amsterdam Health Monitor Survey. J Hypertens 24, 2169-2176.

46. Bulik CM, Wade TD, Heath AC, Martin NG, Stunkard AJ \& Eaves LJ (2001) Relating body mass index to figural stimuli: population-based normative data for Caucasians. Int J Obes Relat Metab Disord 25, 1517-1524.

47. Ogden CL, Carroll MD, Curtin LR, McDowell MA, Tabak CJ \& Flegal KM (2006) Prevalence of overweight and obesity in the United States, 1999-2004. JAMA 295, 1549-1555.
48. Cash TF, Morrow JA, Hrabosky JI \& Perry AA (2004) How has body image changed? A cross-sectional investigation of college women and men from 1983 to 2001. J Consult Clin Psychol 72, 1081-1089.

49. Bennett GG, Wolin KY, Goodman M, Samplin-Salgado M, Carter P, Dutton S, Hill R \& Emmons K (2006) Attitudes regarding overweight, exercise, and health among blacks (United States). Cancer Causes Control 17, 95-101.

50. Cachelin FM, Striegel-Moore RH \& Elder KA (1998) Realistic weight perception and body size assessment in a racially diverse community sample of dieters. Obes Res $\mathbf{6}$, 62-68.

51. Roberts A, Cash TF, Feingold A \& Johnson BT (2006) Are black-white differences in females' body dissatisfaction decreasing? A meta-analytic review. J Consult Clin Psychol 74, 1121-1131.

52. Olvera N, Suminski R \& Power TG (2005) Intergenerational perceptions of body image in Hispanics: role of BMI, gender, and acculturation. Obes Res 13, 1970-1979.

53. Perez M, Voelz ZR, Pettit JW \& Joiner TE Jr (2002) The role of acculturative stress and body dissatisfaction in predicting bulimic symptomatology across ethnic groups. Int J Eat Disord 31, 442-454.

54. Reddy SD \& Crowther JH (2007) Teasing, acculturation, and cultural conflict: psychosocial correlates of body image and eating attitudes among South Asian women. Cultur Divers Ethnic Minor Psychol 13, 45-53.

55. Soh NL, Touyz SW \& Surgenor LJ (2006) Eating and body image disturbances across cultures: a review. Eur Eat Disord Rev 14, 54-65.

56. Wildes JE, Emery RE \& Simons AD (2001) The roles of ethnicity and culture in the development of eating disturbance and body dissatisfaction: a meta-analytic review. Clin Psychol Rev 21, 521-551.

57. Burns CM, Tijhuis MA \& Seidell JC (2001) The relationship between quality of life and perceived body weight and dieting history in Dutch men and women. Int J Obes Relat Metab Disord 25, 1386-1392.

58. Paeratakul S, White MA, Williamson DA, Ryan DH \& Bray GA (2002) Sex, race/ethnicity, socioeconomic status, and BMI in relation to self-perception of overweight. Obes Res 10, 345-350.

59. Canpolat BI, Orsel S, Akdemir A \& Ozbay MH (2005) The relationship between dieting and body image, body ideal, self-perception, and body mass index in Turkish adolescents. Int J Eat Disord 37, 150-155. 